\title{
Perbandingan PKJI 2014 Dan MKJI 1997 Dengan Software Vissim Dalam Menganalisa Dampak Lalu Lintas (Studi Kasus Jalan Jenderal Sudirman Duri)
}

\author{
Indra Fahmi ${ }^{1}$, Vicky Kurniawan ${ }^{2}$, Muhammad Idham ${ }^{3}$ \\ Jurusan Teknik Sipil Politeknik Negeri Bengkalis \\ Jl. Bathin Alam, Sungai Alam, Bengkalis \\ E-mail: fahmi.if14@gmail.com
}

\begin{abstract}
ABSTRAK
Peningkatan volume kendaraan akan mempengaruhi tingkat kinerja lalu lintas dan menyebabkan perubahan perilaku lalu lintas suatu ruas jalan yang akhirnya mengakibatkan terjadinya dampak lalulintas. Metode di Indonesia yang digunakan untuk menganalisa dampak lalu lintas yaitu Pedoman Kapasitas Jalan Indonesia (PKJI 2014) sebagai pemutakhiran dari MKJI 1997. Tujuan penelitian ini adalah untuk mengetahui perbandingan nilai analisis dampak lalu lintas antaraPKJI 2014, MKJI 1997 dan software Vissim dalam menganalisa dampak lalu lintas. Hasil analisa yang diperoleh dari satu segmen jalan yaitu jalan Jenderal Sudirman tersebut akan diketahui melalui kinerja ruas jalan. Setelah dilakukan penelitian dan hasilnya menunjukkan dengan lebar efektif jalan yaitu $6.50 \mathrm{~m}$ Jalan Jenderal Sudirman Duri mengalami kemacetan apabila menggunakan PKJI 2014 dan MKJI 1997 dengan derajat kejenuhan 1.20 sedangkan menggunakan software vissim tidak.
\end{abstract}

Kata kunci: Kinerja lalu lintas, PKJI 2014, MKJI 1997, Software vissim

\begin{abstract}
Rapidly increasing of the vehicle will be influenced by a form of traffic and indicate the change in the behaviour of traffic on the road, finally to the impact of traffic. In Indonesian method to analyze the traffic impact assessment is Indonesia highway capacity as an update form IHCM 1997. The purpose of the research to compare IHCM 2014, IHCM 1997 and Vissim Software to analyze traffic impact assessment. The results of the analysis obtained from one road segment, at Jenderal Sudirman street road will be known through the performance of the road. After doing the research and the results show that the effective width of the road is $6.50 \mathrm{~m}$. Jenderal Sudirman street has congestion when using PKJI 2014 and MKJI 1997 with a degree of saturation of 1.20 while using software vissim is not.
\end{abstract}

Keywords: Form of traffic, IHCM 2014, IHCM 1997, Vissim software

UNITEX Vol 11 No.2 Juli - Desember 2018 | p-ISSN 2089-3957 | e-ISSN 2580-2585 


\section{Pendahuluan}

Transportasi memiliki peranan yang sangat penting bagi kehidupan masyarakat seiring dengan perkembangan zaman. Peningkatan volume kendaraan akan mempengaruhi tingkat kinerja lalu lintas dan menyebabkan perubahan perilaku lalu lintas suatu ruas jalan yang akhirnya mengakibatkan terjadinya dampak lalulintas. Peningkatan ini diakibatkan oleh bertambahnya jumlah penduduk dan kebutuhan akan sarana transportasi, kendaraan yang berhenti dan parkir di badan jalan, penyeberang jalan, dan kendaraan tak bermotor. Adapun metode yang digunakan di Indonesia untuk menganalisa dampak lalu lintas yaitu Pedoman Kapasitas Jalan Indonesia (PKJI 2014) sebagai pemutakhiran dari MKJI 1997.

Jalan Jenderal Sudirman kota duri merupakan salah satu kasus terjadinya dampak lalu lintas akibat adanya parkir kendaraan di badan jalan dikarenakan aktifitas pasar dan pertokoan, sehingga perlu dianalisa dampak lalu lintas untuk mengetahui seberapa besar nilai dari derajat kejenuhan dan dampak yang terjadi. Untuk menganalisa maka diperlukan Perbandingan metode yaitu Pedoman Kapasitas Jalan Indonesia 2104, Manual Kapasitas Jalan Indonesia 1997 dan dengan menggunakan software vissim. Adapun rumusan masalah berdasarkan latar belakang di atas yaitu : Bagaimanakah pengaruh dampak lalu lintas yang terjadi akibat adanya kendaraan yang parkir di badan jalan (On Street Parking) ?Bagaimanakah perbandingan nilai analisis dampak lalu lintas antara Pedoman Kapasitas Jalan Indonesia (PKJI 2014), Manual Kapasitas Jalan Indonesia (MKJI 1997), dan software Vissim akibat adanya konflik lalu lintas di ruas jalan tersebut?.

\section{Metode Penelitian}

Survey ini dilakukan untuk mengetahui volume kendaraan yang ada diruas jalan tinjauan selama 40 jam. Adapun cara surveinya yaitu:

a. Tentukan lokasi penelitian

b. Tentukan periode waktu pelaksanaan survei (per 15 menit)

c. Siapkan form survei yang akan digunakan

d. Lalu catat jumlah volume kendaraan yang masuk dan keluar ruas jalan dengan panjang $200 \mathrm{~m}$ (area tinjauan) berdasarkan tiap jenis kendaraan 
Survei Kecepatan Kendaraan

Dalam pelaksanaan survei kecepatan kendaraan digunakan jarak $100 \mathrm{~m}$ dibagi dua segmen per jalur. Adapun cara survei kecepatan yaitu:

a. Tentukan lokasi penelitian

b. Tandai titik lokasi tinjauan kendaraan yang akan diamati (persegmen).

Amati kendaraan yang masuk kedalam titik lokasi tinjauan sesuai segmen yang telah dibagi berdasarkan jarak $50 \mathrm{~m}$ persegmen lalu catat waktu kendaraan yang melewati titik tinjauan menggunakan stopwatch. Adapun tempat yang dijadikan objek penelitian ini yaitu di ruas jalan Sudirman Kota Duri disepanjang area pasar dan pertokoan $(200 \mathrm{~m})$. Waktu pelaksanaan pengambilan data dilakukan selama 40 jam.

Diagram Alir

Dalam melakukan penelitian ini diperlukan tahapan-tahapan untuk membuatnya agar dapat diketahui langkah awal sampai akhir yang harus dilakukan dalam penulisan. 


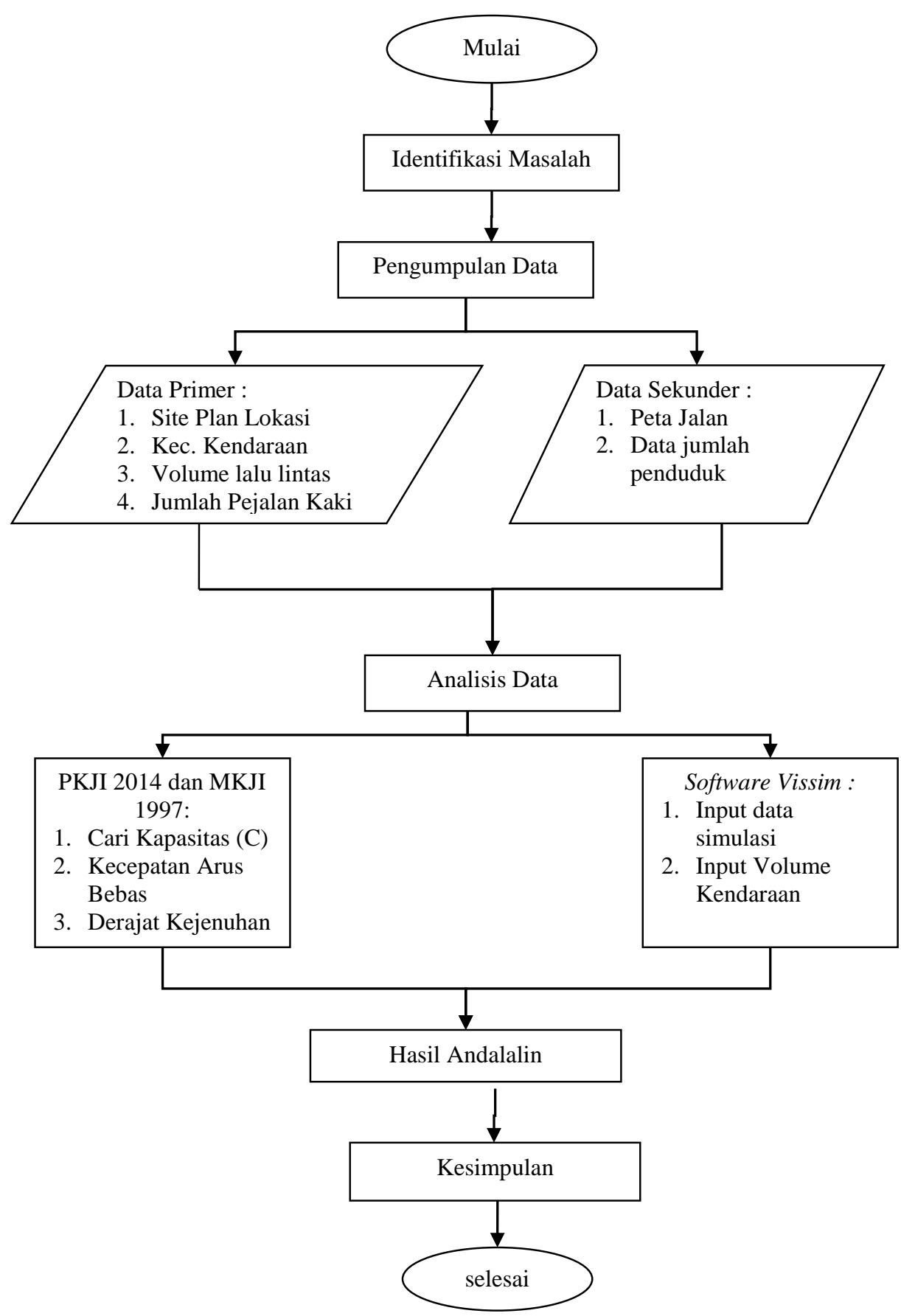

Gambar 1. Bagan alir pelaksanaan

UNITEX Vol 11 No.2 Juli - Desember 2018 | p-ISSN 2089-3957 | e-ISSN 2580-2585 


\section{Hasil Dan Pembahasan}

\section{Analisa Kinerja Ruas Jalan Existing Menggunakan PKJI 2014}

A. Kecepatan Arus Bebas

Untuk menganalisis kecepatan arus bebas, maka didapat kecepatan arus bebas untuk Kendaraan Ringan (KR) dengan menggunakan persamaan sebagai berikut:

$\mathrm{VB}=(57+-2) \times 0.92 \times 0,95$

$\mathrm{VB}=48.07 \mathrm{~km} / \mathrm{jam}$

Dari hasil perhitungan maka diperoleh nilai Kecepatan Arus Bebas (VBKR) Jalan Sudirman-Duri adalah $48.07 \mathrm{~km} / \mathrm{jam}$.

B. Kapasitas (C)

Kapasitas dasar jalan 2 arah $2205 \mathrm{skr} / \mathrm{jam}$, untuk faktor penyesuaian kapasitas lebar jalur adalah 0.96, faktor penyesuaian pemisah arah arus lalulintas adalah 1.00, faktor penyesuaian akibat Kelas Hambatan Samping adalah 0.92, dan faktor penyesuaian kapasitas kota adalah 0.94. Maka kapasitas total untuk ruas Jalan Sudirman-Duri dapat dihitung dengan menggunakan persamaan:

$\mathrm{C}=2205 \times 0.96 \times 1.00 \times 0,92 \times 0,94$

$\mathrm{C}=1831 \mathrm{skr} / \mathrm{jam}$

Jadi kapasitas total ruas Jalan Sudirman-Duri adalah sebesar 1831 skr/jam. Berdasarkan perhitungan kapasitas tersebut terdapat nilai Derajat Kejenuhan (DJ) dengan perhitungan sebagai berikut:

$\mathrm{DJ}==1.20$

Dari hasil yang diperoleh bahwa DJ $=1.20>0.85$ sehingga kinerja ruas Jalan Sudirman-Duri mengalami kemacetan atau penumpukan arus lalulintas.

\section{Analisa Kinerja Ruas Jalan Existing Menggunakan MKJI 1997}

A. Kecepatan Arus Bebas

Untuk menganalisis kecepatan arus bebas, maka didapat kecepatan arus bebas untuk kendaraan ringan (LV) dengan menggunakan persamaan sebagai berikut:

$\mathrm{VB}=(57+-2) \times 0.92 \times 0.95$

$\mathrm{VB}=48.07 \mathrm{~km} / \mathrm{jam}$

Dari hasil perhitungan maka diperoleh nilai kecepatan arus bebas (FVo) Jalan Sudirman-Duri adalah $48.07 \mathrm{~km} / \mathrm{jam}$.

UNITEX Vol 11 No.2 Juli - Desember 2018 | p-ISSN 2089-3957 | e-ISSN 2580-2585 
B. Kapasitas (C)

Kapasitas dasar jalan 2 arah $2205 \mathrm{Smp} / \mathrm{jam}$, untuk faktor penyesuaian kapasitas lebar jalur adalah 0.96, faktor penyesuaian pemisah arah arus lalu lintas adalah 1.00, faktor penyesuaian akibat kelas hambatan samping adalah 0.92, dan faktor penyesuaian kapasitas kota adalah 0.94. Maka kapasitas total untuk ruas Jalan Sudirman-Duri dapat dihitung dengan menggunakan persamaan:

$\mathrm{C}=2205 \times 0.96 \times 1.00 \times 0.92 \times 0.94$

$\mathrm{C}=1831 \mathrm{Smp} / \mathrm{jam}$

Jadi kapasitas total ruas Jalan Sudirman-Duri adalah sebesar 1831 Smp/jam. Berdasarkan perhitungan kapasitas tersebut terdapat nilai derajat kejenuhan (Ds) dengan perhitungan sebagai berikut:

Ds $=\frac{2205}{1831}$

$\mathrm{Ds}=1.20$

Dari hasil yang diperoleh bahwa $\mathrm{Ds}=1.20>0.85$ sehingga kinerja ruas Jalan Sudirman-Duri mengalami kemacetan atau penumpukan arus lalu lintas.

\section{Analisa Kondisi Jalan Existing Menggunakan Software Vissim}

\section{A. Hasil Simulasi}

Simulasi menggunakan software vissim ini berdasarkan data-data yang didapat dari survei lapangan dengan lebar jalan efektif $6.50 \mathrm{~m}$ dimana hasil simulasi sebagai berikut:

Tabel 1. Hasil percobaan simulasi

\begin{tabular}{|c|c|c|c|}
\hline Arah & $\begin{array}{c}\text { Jumlah } \\
\text { Kendaraan } \\
\text { (Data Survei) }\end{array}$ & Hasil Simulasi & Keterangan \\
\hline Timur - Barat & 2763 & $\begin{array}{c}\text { Tidak Terjadi } \\
\text { Kesalahan }\end{array}$ & $\begin{array}{c}\text { Tidak macet } \\
\text { (kapasitas jalan } \\
\text { tidak terlampaui) }\end{array}$ \\
\hline Barat - Timur & 2652 & $\begin{array}{c}\text { Tidak Terjadi } \\
\text { Kesalahan }\end{array}$ & $\begin{array}{c}\text { Tidapas } \\
\text { tidak terlas jalan } \\
\text { tidanai) }\end{array}$ \\
\hline
\end{tabular}

Setelah dilakukan simulasi pada percobaan pertama hasil yang didapat ternyata jalan tidak mengalami masalah dan tidak terjadinya kemacetan, ini menunjukkann bahwa kapasitas jalan tidak terlampaui dan semua kendaraan bisa disimulasikan. 


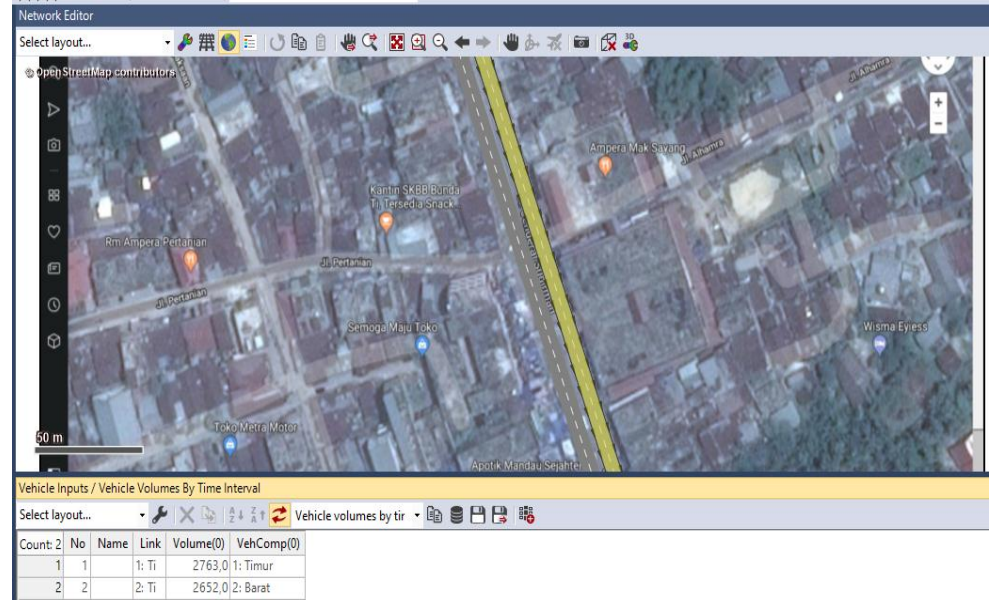

Gambar 2. Hasil Simulasi Menggunakan Software Vissim

Berdasarkan Gambar 2 menunjukkan bahwa kapasitas jalan arah TimurBarat dan arah Barat-Timur telah terlampaui dengan ditandai munculnya pesan pemberitahuan bahwa ada sejumlah kendaraan yang tidak bisa tersimulasikan.

\section{Hasil Analisa}

Hasil analisa antara PKJI 2014, MKJI 1997 dan software Vissim yaitu:

Tabel 2. Perbandingan hasil analisis

\begin{tabular}{|c|c|c|c|}
\hline Metode & Arah & $\begin{array}{c}\text { Jumlah } \\
\text { Kendaraan } \\
\text { (Data Survei) }\end{array}$ & Hasil analisis \\
\hline $\begin{array}{c}\text { PKJI 2104 } \\
\text { dan MKJI } \\
1997\end{array}$ & Timur - Barat & 2763 & \multirow{2}{*}{ Ruas jalan macet } \\
\cline { 2 - 3 } & Barat - Timur & 2652 & $\begin{array}{c}\text { Ruas jalan tidak } \\
\text { macet (kapasitas } \\
\text { jalan tidak } \\
\text { terlampaui) }\end{array}$ \\
\cline { 1 - 3 } $\begin{array}{c}\text { Software } \\
\text { Vissim }\end{array}$ & Timur - Barat & 2763 & \\
\cline { 2 - 3 } & Barat - Timur & 2652 & \multicolumn{2}{|c|}{} \\
\hline
\end{tabular}

Berdasarkan Tabel 2 menunjukkan bahwa dengan jumlah kendaraan yang sama hasil analisa hitungan menggunakan PKJI 2014 dan MKJI 1997 jalan Jenderal Sudirman Duri mengalami kemacetan dengan nilai Dj 1.20 sedangkan hasil analisa menggunakan Software Vissim ruas jalan tidak mengalami kemacetan sehingga hasil yang didapat menggunakan kedua metode ini tidak sama. Perhitungan dengan menggunakan PKJI 2014 dan MKJI 1997 ditentukan

UNITEX Vol 11 No.2 Juli - Desember 2018 | p-ISSN 2089-3957 | e-ISSN 2580-2585 
berdasarkan nilai DJ > 0.85 dengan ketentuan bahwa kapasitas jalan mengalami kemacetan atau kapasitas jalan telah terlampaui dari batas kapasitas dasar 1650 skr/jam untuk jalan tipe 4/2 T, sedangkan menggunakan software vissim didapat melalui proses simulasi kendaraan dengan menghasilkan jumlah kendaraan melalui proses trial and error volume kendaraan dan berdasarkan ketentuan jika kendaraan yang tidak dapat tersimulasi bahwa kapasitas jalan telah terlampaui.

\section{Simpulan}

Dari hasil perhitungan dan analisis penelitian didapatkan kesimpulan bahwa:

A. Dari hasil hitungan volume dengan kapasitas nilai derajat kejenuhan yang didapat lebih besar dari batas nilai yang telah ditetapkan PKJI 2014 dan MKJI 1997 yaitu DJ $1.20>0.85$ sehingga nilai v/c dikategorikan tinggi.

B. Simulasi vissim yang disesuaikan dengan data kondisi existing lapangan dengan lebar efektif jalan $6.50 \mathrm{~m}$ tidak mengalami kemacetan atau kapasitas jalan tidak terlampaui, sedangkan berdasarkan hitungan PKJI 2014 dan MKJI 1997 kondisi jalan mengalami kemacetan dengan derajat kejenuhan 1.20 .

\section{Daftar Pustaka}

Departemen Pekerjaan Umum. (2014). Pedoman Kapasitas Jalan Indonesia, Direktorat Jenderal Bina Marga, Jakarta.

Departemen Pekerjaan Umum. (1997). Manual Kapasitas Jalan Indonesia, Direktorat Jenderal Bina Marga, Jakarta.

Halimah, I. (2017). Analisis Dampak lalu lintas (Andalalin) Kondisi Eksisting Jalan Bathin ALam Sungai ALam (Studi Kasus: Kampus Politeknik Negeri Bengkalis). Skripsi. Jurusan Teknik Sipil, Politeknik Negeri Bengkalis, Bengkalis.

Haryadi, D., Tajudin, I., Muchlisin. (2017). Modul Pembelajaran Traffic MicroSimulation Program PTV. Vissim 9. Jurusan Teknik Sipil, Universitas Muhammadiyah Yogyakarta, Yogyakarta. 
Lalenoh, R,H., Sendow, T,K., Jansen, F., (2015), Analisa Kapasitas Ruas Jalan Sam Ratulangi Dengan Metode MKJI 1997 dan PKJI 2014, Jurnal Sipil Statik Vol.3, Manado.

PT. Putera Mataram Mitra Sejahtera, (2006), Analisis Dampak Lalu Lintas Plaza Ambarrukmo, Fakultas Teknik Universitas Gajah Mada.

Tamin, O.,Z. (2000) Perencanaan dan Permodelan Transportasi, Percetakan ITB, Bandung

Widodo, A.,S, 2007, Analisis Dampak lalu lintas (Andalalin) Pada Pusat Perbelanjaan Yang Telah Beroperasi Ditinjau Dari Tarikan Perjalanan (Studi Kasus Pada Pacific Mall Tegal), Tesis, Program Magister Teknik Sipil Jurusan Manajemen Rekayasa Infrastruktur, Universitas Diponegoro, Semarang.

Winnetou, I,A., dan Munawar, A., (2015), Penggunaan Software Vissim Untuk Evaluasi Hitungan MKJI 1997 Kinerja Ruas Jalan Perkotaan, FSTPT International Symposium, Yogyakarta. 